\title{
Satisfaction of supplementary insurance for medicinal services in war survivors in Iran
}

\author{
Batool Mousavi ${ }^{1}$, Mohammadreza Soroush ${ }^{1}$, Farzaneh Maftoon*2, Kazem Mohammad ${ }^{3}$, \\ Ali Ayoubian ${ }^{4}$
}

Received: 31 Oct 2016

Published: 9 Jul 2019

Conflicts of Interest: None declared

Funding: None

*This work has been published under CC BY-NC-SA 1.0 license.
Copyright $\subseteq \underline{\text { Iran University of Medical Sciences }}$

Cite this article as: Mousavi B, Soroush M, Maftoon F, Mohammad K, Ayoubian A. Satisfaction of supplementary insurance for medicinal services in war survivors in Iran. Med J Islam Repub Iran. 2019 (9 Jul);33:66. https://doi.org/10.47176/mjiri.33.66

\section{Brief Communication}

Health as a vital concept and a priority of each society mean lacking physical and mental diseases and disabilities as well as social and economic issues. Based on this definition (WHO) health is a multi-dimensional subject nowadays that consists of not only social, physical and mental elements but also economic aspects too $(1,2)$. It has to be mentioned that different aspects of health and diseases are affecting each other. This means physical issues affect the mental situations and vice versa, also these two can influence the community, and subsequently, the community disorders affect every individual's health. Thus applied approaches with the aim of health development must be considered both in the individual and social levels (3).

Marvelous improvement of medical science during the past decades in association with modern technologies provided a noble opportunity to cure diseases that were not treatable previously. Experiments and modern scanners are new detection instruments that can be taken advantage

Corresponding author: Dr Farzaneh Maftoon, fmaftoon@ihsr.ac.ir

1. Prevention Department, Janbazan Medical and Engineering Research Center (JMERC), Tehran, Iran

2. Health Metrics Research Center, Iranian Institute for Health Sciences Research, ACECR, Tehran, Iran

3. Department of Epidemiology and Biostatistics, Health Faculty, Tehran University of Medical Sciences, Tehran, Iran

4. National Center for Health Insurance Research, Iran Health Insurance Organization, Tehran, Iran by the physicians. Surgeries have turned back many patients from death as well. Despite these developments and hopes that are given by these treatments, due to expensive costs, they are not affordable for many people yet. Even treatment insurances are not able to cover these costs. In this situation, using supplementary insurances seems to be a perfect alternative which can be applied both individually and through a group (4). This insurance includes a spread range of services such as para-clinical services, medicinal providing services, and even unlimited services. And also many alternatives for the patient including choosing the treatment centers (private or governmental) and even the kind of the treatment services such as dental, surgical and others are among the most important benefits of the supplementary insurance. The objective of the following study was to evaluate the satisfaction of war survivors and their families under cover of supplementary insurance for receiving medicinal services.

This study was a cross-sectional descriptive. The studied community was war survivors and their families who

$\uparrow$ What is "already known" in this topic:

Most of the burden of the cost for medication is referred to the government and supplementary insurances, which are vital to burden extra costs of specific treatments. A national system for client satisfactory has not organized yet in Iran, and the actions are only locally applied. For the first time, this study focused on the satisfaction of medical services in war survivors covered by supplementary insurance.

\section{$\rightarrow$ What this article adds:}

The survey revealed a high rate of prescriptions in the studied population $(\% 85.5)$. The most important determinant of poor satisfaction of supplementary insurance in war survivors who needed medicinal services was the far distance of the pharmacy. More than half paid out of their own pocket, so paying back the costs by the insurance company needs more reconsiderations and modifications. 
were assessed by the provided questionnaire in 2016. Subjects $(\mathrm{N}=1558)$ were selected randomly according to VMAF statistics among eligible individuals. Including criteria were martyr families, veterans, and their families under cover of supplementary insurance that needed medication.

The produced questionnaire included two parts; personal information (sex, age, relativity, occupation, education, residency, and using supplementary insurance) and satisfaction questionnaire of supplementary insurance services on pharmacies. Satisfaction questionnaire was organized in the field of medication receiving services. A questionnaire was provided with open question by the main researchers primarily, then modified to closed questions. For academic validation, the provided questionnaire was propounded to scientific administrators who had experience in the field, and after gaining specific comments, the amendments were applied. Study scientific confidence development was achieved by the second examination method. It was obtained through filling the questionnaires by subjects of the study and the confidence of the questionnaire with $\mathrm{r}=0.8$ was obtained. These subjects were eluted from the statistical population finally. Reliability assessment was obtained by internal consistency coefficient (Cronbach's alpha) with 0.84 . The satisfaction was defined in three areas, including service satisfaction itself, the service distance satisfaction, and the cost refund satisfaction. Service Satisfaction means the satisfaction of the person who took the service in the time of questioning from the whole process in which he/she has received the service in the pharmacy. Service distance satisfaction means being satisfied with the distance from the pharmacy where the service was delivered. Cost refund satisfaction means the satisfaction of all procedures that the subject has endured to receive back the costs from the supplementary insurance. In each field, the satisfaction index was quantified by the subjects based on a Likert scale from very bad to very good marking 1 to 5 . To comply with research ethics, the study procedure was explained to all the subjects by the researchers primarily and they were assured that all the information is confidential and participating in this study was totally voluntary. Subjects were chosen from Veterans and Martyrs Affair Foundation (VMAF) databank randomly. The data was gained by expert interviewers through phone calls for two months. For each subject, the telephone call was made three times, and in case of no answer, the subject was substituted by another random subject. The analysis was done by SPSS version 21 software using K-squared test. A p-value of less than 0.05 were considered as significant. Logistic regression used for detecting factors associated with the risk of dissatisfaction of services in the pharmacy, such as service distance satisfaction for pharmacy centers and cost refund satisfaction.

Most of the war survivors and their families (85.5\%) who were visited by the physician $(n=1823)$ required medication $(n=1558)$. The mean age of the participants was $51.62(\mathrm{sd}=17.2)$. The majority of the cases were male $56.8 \%(\mathrm{n}=885)$ and married $82.6 \%(\mathrm{n}=1282)$. About $14.3 \%(n=213)$ of participants were living in rural areas.
Most of them had a diploma or higher education $75.6 \%$ (1178) and employed $68.9 \quad(n=1075)$. About $70.6 \%$ $(n=1096)$ used service facilities with their supplementary insurance and used pharmacies that had a contract with their supplementary insurance company. All participant were under cover of the supplementary insurance. However, $29.4 \%(n=456)$ paid out of pocket for needed medications. Of these, $66.1 \%(n=301)$ did not succeed to get their expenses back.

Logistic regression used to detect factors associated with the risk of dissatisfaction from received medication and service distance satisfaction is demonstrated in Table 1. As shown in Table 1 (B), the most important determinant of poor satisfaction in war survivors was the distance of pharmacies for people living in a rural area $(\mathrm{p}<0.0001)$. None of the variables increased the risk of dissatisfaction by service cost refund among the studied population $(\mathrm{p}>.05)$.

Satisfaction among different countries with similar health outcomes is widely varied. Finance and delivery cannot justify the difference in satisfaction ratings among them. For instance, Austria and Spain have universally accessible systems that are publicly financed through taxes, but only $10.8 \%$ of Spaniards claimed to be very satisfied, in comparison with $70.4 \%$ of Austrians (5), leading population satisfaction in Austria above the European average (6). Other countries in the United European region are pioneers in this subject as well (7).

Public health insurance in most developed countries is universal but incomplete and mostly takes care of 20 to 30 percent of all spending ( $25 \%$ in France, for instance). Subsequently, most people should apply for supplemental health insurance. These kinds of insurances have the most important role for the patients to choose the type of treatment, the centers, physicians, and the experiments (8). It also places greater weight on understanding and addressing the role of physician and patient in determining health care utilization (9). Little is known about which physician is more likely to accept or reject a patient's request, and its causes. However, it is suggested to assess the nature, frequency, and impact of such requests in this particular population, especially disables, war survivors, and elders. In Iran, however, a national system for client satisfactory has not organized yet, and the actions are only locally applied. Based on the occupation of the people in Iran, there are different governmental insurance, that compensates about $30 \%$ of the medication costs in maximum (10). So, supplementary insurances are vital to aid the extra costs of specific treatments.

The categories were: (1) the concept of patients' rights; (2) barriers to patients' rights; and (3) facilitators of patients' rights. The distinctive themes within each of the categories were identified as (1a) receiving real care, (1b) focus on the patient, and (1c) equality and accessibility; (2a) dissatisfaction with caregivers, and (2b) specific work environment limitations; (3a) the patient's companion, (3b) a responsible system, and (3c) the public's awareness of rights. Although certain themes identified closely resemble those identified in international patients' bills of rights, the current study focused on themes that are partic- 
Table 1. Results of Logistic Regression

\begin{tabular}{|c|c|c|c|c|c|c|c|c|}
\hline \multicolumn{9}{|c|}{ A) Determinants of poor satisfaction for medication in war survivors used supplementary insurance } \\
\hline \multirow{3}{*}{ Sex: } & \multirow{2}{*}{\multicolumn{2}{|c|}{ Female }} & \multirow[t]{2}{*}{ B } & \multirow[t]{2}{*}{ Wald } & \multirow[t]{2}{*}{ Sig. } & \multirow{2}{*}{$\begin{array}{c}\text { OR } \\
0 \text { (ref) }\end{array}$} & Lower & Upper \\
\hline & & & & & & & & \\
\hline & Male & & -0.22 & 0.315 & 0.575 & 0.803 & 0.373 & 1.729 \\
\hline \multirow{2}{*}{\multicolumn{2}{|c|}{ Marital status: }} & Married & & & & 1.0 (ref.) & & \\
\hline & & Single & -0.244 & 0.47 & 0.493 & 0.783 & 0.389 & 1.576 \\
\hline \multirow[t]{3}{*}{ Age: } & $>=60$ & & & 1.524 & 0.467 & 1.0 (ref.) & & \\
\hline & $40-59$ & & -0.433 & 1.418 & 0.234 & 0.649 & 0.318 & 1.323 \\
\hline & $<40$ & & -0.32 & 0.494 & 0.482 & 0.726 & 0.298 & 1.773 \\
\hline \multirow[t]{3}{*}{ Group: } & Veteran & family & & 13.286 & 0.001 & 1.0 (ref.) & & \\
\hline & Martyrs & amily & -1.36 & 6.015 & 0.014 & 0.257 & 0.087 & 0.761 \\
\hline & Veteran & & 0.067 & 0.011 & 0.918 & 1.07 & 0.296 & 3.873 \\
\hline Constant & & & 4.245 & 58.09 & $<0.0001$ & 69.744 & & \\
\hline
\end{tabular}

B) Determinants of poor satisfaction in the distance of pharmacies in war survivors used supplementary insurance

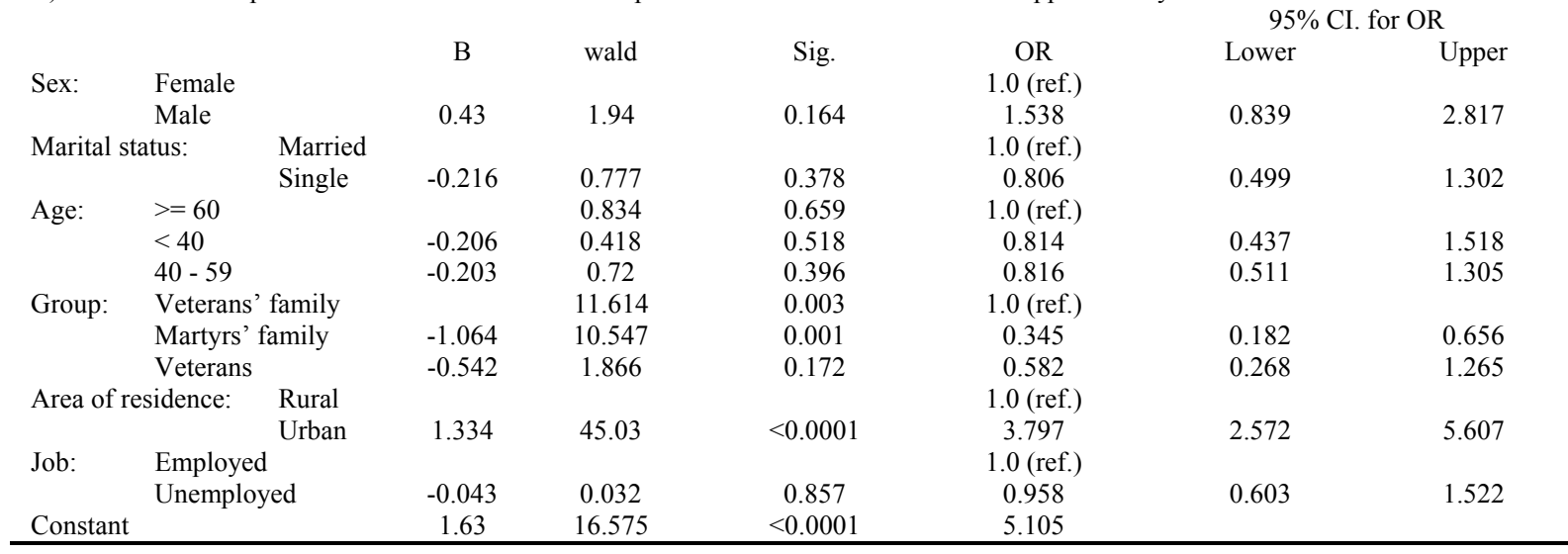

ularly relevant to the Iranian sociocultural context.

The studied population who used supplementary insurance had sati sfaction with the mean of 4.54 (out of 5 ), that was in compliance with other developing countries $(11,12)$, maximum and minimum satisfaction belong to veterans (of 4.75) martyrs' families (4.11), respectively. However, an appropriate satisfaction mean the consequence of lacking some specific medications due to US embargo restrictions against the Islamic Republic of Iran cannot be missed (13). This, lead to inaccessibility and not receive real care, which might cause more dissatisfaction as Joolaee et al. believe (14). The less satisfaction in medicinal services offer by supplementary insurance was related to the cost refund services with a mean of 2.6 (out of 5). The means were low for veterans as well as family members with no significant difference. Health system modifications policies seem necessary to improve the satisfaction of Iranians especially martyrs' families, veterans and their families who needed to be obtained by negotiation between the employment organization (VMAF) and the insurance companies. The cost refund satisfaction was less than service distance satisfaction. It is necessary to investigate the causes of not receiving the demands on time, including incomplete or delayed payment and bureaucracy or other causes.

Analysis of the obtained results indicated that living in rural areas is the most effective risk factors that increased dissatisfaction in the studied population. Accessing to health services for rural populations is always challenging. The main challenge is reaching for the services on time and continuously. These challenges lead to inequality for receiving services for people in rural areas. Furthermore, to be far from big cities affect receiving the medication from the supplementary insurance and make these individuals pay the costs out of their own pockets. Thus, in order to improve satisfaction in health care recipients who live in rural areas and need medications for long time due to their chronic conditions, appropriate alternatives should be considered.

The study revealed a high rate of prescriptions in the studied population. This produces more burden on the health care system, so the physicians' role in proper prescriptions are important to avoid unnecessary costs.

Although the overall satisfaction of the participants who were under cover of supplementary insurance from pharmacy services is appropriate, cost refund by the insurance company was less satisfactory and needs more reconsiderations.

\section{Acknowledgments}

We would like to thank all the war survivors and their families for their kind cooperation during this study. We would also like to express our gratitude towards the VMAF staff: Abdolreza Abbaspour, Iraj Arabi, Davood Rahimpoor, Ali Khoubyarian, Saeed Attari, Reza Valian, Ali Nasiri, Ali Palizgir, Hasan Godarzy, Seyed Hamidreza Mottaghi, Mohammadreza Eslami, Esmaeil Eslami and Sayyed Mohammad Mahdi Shahravesh for preparing the data, as well as, helping in understanding the pharmaceutical and medication services offered by complementary medicine. 


\section{Conflict of Interests}

The authors declare that they have no competing interests.

\section{References}

1. Habersack M, Luschin G. WHO-definition of health must be enforced by national law: a debate. BMC Med Ethics. 2013;14(1):1.

2. Kohn J. What is health? A multiple correspondence health index. East Econ J. 2012;38(2):223-50.

3. Tambor M, Pavlova M, Rechel B, Golinowska S, Sowada C, Groot W. Willingness to pay for publicly financed health care services in Central and Eastern Europe: Evidence from six countries based on a contingent valuation method. Soc Sci Med. 2014;116:193-201.

4. Weaver KE, Rowland JH, Bellizzi KM, Aziz NM. Forgoing medical care because of cost. Cancer. 2010;116(14):3493-504.

5. Bleich SN, Özaltin E, Murray CJ. How does satisfaction with the health-care system relate to patient experience? Bullet World Health Organ. 2009;87(4):271-8

6. Hofmarcher MM, Quentin W. Austria: health system review. Health Syst Transit. 2012;15(7):1-292.

7. Mossialos E, Thomson S, World Health Organization. Voluntary health insurance in the European Union. Copenhagen: WHO Regional Office for Europe; 2004.128

8. Buchmueller TC, Couffinhal A, Grignon M, Perronnin M. Access to physician services: does supplemental insurance matter? Evidence from France. Health Econ. 2004;13(7):669-87.

9. Kravitz RL, Bell RA, Azari R, Kelly-Reif S, Krupat E, Thom DH. Direct observation of requests for clinical services in office practice: what do patients want and do they get it? Arch. Intern. Med. 2003;163(14):1673-81.

10. Ibrahimipour H, Maleki MR, Brown R, Gohari M, Karimi I, Dehnavieh R. A qualitative study of the difficulties in reaching sustainable universal health insurance coverage in Iran. Health Policy Plan. 2011;26(6):485-95.

11. Bernhart MH, Wiadnyana I, Wihardjo H, Pohan I. Patient satisfaction in developing countries. Soc Sci Med. 1999;48(8):989-96.

12. Al-Abri R, Al-Balushi A. Patient satisfaction survey as a tool towards quality improvement. Oman Med J. 2014;29(1):3-7.

13. Namazi S. Sanctions and medical supply shortages in Iran. Viewpoints. 2013;20.

14. Joolaee S, Nikbakht-Nasrabadi A, Parsa-Yekta Z, Tschudin V, Mansouri I. An Iranian perspective on patients' rights. Nurs Ethics. 2006;13(5):488-502. 